\title{
RESIDENTS’ PERCEPTION OF THE SOCIAL-CULTURAL IMPACTS OF THE 2008 FORMULA 1 SINGTEL SINGAPORE GRAND PRIX
}

\author{
ELAINE CHENG* and NIGEL JARVIS $\dagger$ \\ *Ngee Ann Polytechnic, Singapore \\ $\dagger$ University of Brighton, UK
}

\begin{abstract}
The Formula 1 Grand Prix was held in Singapore for the first time in September 2008. While Singapore had previous experience hosting international events, nothing in the past could be compared to this inaugural event because it brought with it a unique set of impacts, as evidenced by past research into car races held elsewhere. For this reason, this study explores how this major motor sport event impacted its host residents through their perceptions of social-cultural aspects. This is important because it can affect the well-being and quality of the life of local residents, two necessary antecedents for their continued support of the car race in the future. A survey of 96 residents was conducted to elicit responses to host residents' perceptions of social-cultural impacts of the F1. Chi-square analysis was used to explore relationships between different types of respondents and their perceived social-cultural impacts. Residents were largely homogenous with regard to attitudes toward the positive and negative impacts, although there were more discrepancies associated with the negative issues. Results were compared to previous studies of car race events and social exchange and social representation theories were used to help contextualize the data. While residents largely supported the F1 event suggestions were provided so as to better manage the social-cultural impacts.
\end{abstract}

Key words: Social impacts; Motor sport events; Resident perceptions; Social exchange theory; Social representation theory

\section{Introduction}

Large-scale sporting events have become a recent phenomenon in Asia, targeting either specific interest groups or appealing to the wider general population (Dolles \& Söderman, 2008). The FIFA World Cup 2002 in South Korea and Japan and the recent Olympic Games 2008 in Beijing are two very good examples of Asian host countries and cities that have used events to propel their images to a global audience and market their destinations in a bid to attract visitors (Brown, Chalip, Jago, \& Mules, 2002; Deccio \& Baloglu, 2002; Fredline \& Faulkner, 2002a; Jago, Chalip, Brown, Mules, \& Ali, 2003; Jones, 2001). Singapore is no exception.

In 2007, Singapore won the hosting rights for the Formula 1 Grand Prix. Touted to boost tour- 
ism, it was anticipated to draw 80,000 spectators, comprised mainly of tourists but also local residents, and generate about SGD $\$ 100$ million in incremental tourism receipts (Ministry of Trade \& Industry, 2008). The local media reported the hotel, retail, and entertainment sectors would also benefit as a result. The emphasis here, without a doubt, was on the economic contributions of the event, a critical factor to gain approval and support from stakeholders.

However, a shift in recent years has veered towards assessing additional impacts of events, notably the social-cultural impact (Boyko, 2008; Cegielski \& Mules, 2002; Fredline, 2005; Richards, 2007; Small, 2007). These have major effects on the well-being and quality of life for host residents, a major group of stakeholders, and act as antecedents to gain host residents' support, and are necessary for the sustainability of all events hosted by a destination (Gursoy \& Rutherford, 2004; Twynam \& Johnston, 2004).

Being an inaugural event in Singapore, the 2008 Formula 1 Grand Prix provided an excellent opportunity to explore how this international event impacted host residents from a social-cultural perspective. Past research has been undertaken on host residents' perceptions of social-cultural impacts of motor car races but these were all conducted in Australia: Canberra (V8 Supercar Race), Melbourne (Formula 1 Grand Prix), and the Gold Coast (Indy Car Race) (Cegielski \& Mules, 2002; Fischer, Hatch, \& Paix, 1986; Fredline, 2004; Fredline \& Faulkner, 1998, 2002a, 2002b). While many similarities were found in those studies with regard to the type of impacts, which will be discussed later, the interactions between visitors and host residents, combined with the nature of the event, often produce different results (Small, Edwards, \& Sheridan, 2005). Therefore, research was undertaken on the social-cultural impacts of the Formula 1 car race, based on the perceptions of host residents of Singapore, to compare how a Southeast Asian destination may be affected or not to other countries hosting a major sporting event. Further, Event Management has not recently published social-cultural impact research linked to major sport events since 2002 and before when articles focused on motor sport in the Gold Coast, the America's Cup in Auckland, and the Sydney
Olympics (Barker, Page, \& Meyer, 2002; Faulkner et al., 2001; Fredline \& Faulkner, 2002a, 2002b).

\section{The Social-Cultural Impacts of (Sport) Events}

One of the main reasons for the growth of events is the fact that many authorities now use them as part of the branding strategy for the destination (Jago et al., 2003). Events help to position and reposition a city as international or global (Dwyer, Mellor, Mistilis, \& Mules, 2000; Jones, 2001; Waitt, 2003). In addition, the media effect of the publicity received goes beyond the geographical limit of the destination (Fredline \& Faulkner, 2000). There can be a strong sense of civic pride (Dwyer et al., 2000; Fredline, 2005; Waitt, 2003) as the event is a demonstration of the capability of the host. Events are also used for economic regeneration as they can revive the economy, act as a source for tax revenues, improve infrastructure, and also provide a legacy (Dwyer et al., 2000; Getz, 2007; Kim, Gursoy, \& Lee, 2006; Waitt, 2003). Furthermore, events can also be used to bring attention to environmental issues, thus helping to preserve or improve certain aspects of the environment, ensuring sustainability (Getz, 2007).

However, despite these strong reasons for the growth of events, there are many costs. For example, the environment can be affected through pollution, littering, and a deterioration of natural resources (Barker et al., 2002; Gursoy \& Kendall, 2006). Social issues such as traffic congestion, crime, and undesirable behavior like drunkenness can occur (Barker et al., 2002; Kim et al., 2006; Ohmann, Jones, \& Wilkes, 2006). Traditions and cultures may be trivialized through commercialization, commodification, and acculturation (Besculides, Lee, \& McCormick, 2002; Brunt \& Courtney, 1999; Cohen, 1988). The demonstration effect may also be in evidence (Brunt \& Courtney 1999; Fredline, 2005) and overall there can be a general disruption to the lifestyle of host residents (Dwyer et al., 2001). Fredline, Jago, and Deery (2003a) described social impacts as "any impacts that potentially have an impact on quality of life for local residents" (p. 26). However, as simple as this definition seems, its implications are more significant, as inherent in the term "quality of life" 
are economic and environmental effects of the event.

As authorities pursue the hosting of events as part of their tourism development plans, the study of the social-cultural impacts of events take on more significant importance as residents become more affected by the recurrence of these events. Being a major stakeholder within a destination where events are held, residents' well-being and subsequent support must be considered to ensure the long-term viability of events (Ap \& Crompton, 1998; Fredline \& Faulkner, 2002b). While many studies have concentrated on the economic aspects of events (Jones, 2001; Wood, 2005), mainly because they provide a good basis for eliciting tangible benefits to gain support from authorities of the host destination (Ap \& Crompton, 1998; Deccio \& Baloglu, 2002; Pizam, 1978) and to measure an event's success (Douglas, Douglas, \& Derrett, 2001), adding social objectives to event projects have gained acceptance since the 1980s (Wood, 2005). This is because the staging of events has a profound impact on the social structure of the host destination, leading to changes in various aspects of life (Brunt \& Courtney, 1999). In particular, due to the contact among different cultures as a result of visitor influx, the social values and cultural practices of the host destination could be challenged and altered (Ap \& Crompton, 1993; Johnson, Snepenger, \& Akis, 1994). In addition, a hallmark or mega-event will often elicit a series of related subevents that enhance the lifestyle of host communities (Kim \& Petrick, 2005). Therefore, such social-cultural impacts could be seen as a critical part of an event's success.

However one defines social-cultural impacts or how these impacts are assessed, some will be perceived positively whilst others negatively. Examples of positive social-cultural impacts include promoting cultural exchange and identity (Kim et al., 2006; Waitt, 2003); enhancing destination image (Cegielski \& Mules, 2002; Fredline, 2005; Mihalik \& Simonetta, 1999; Xiao \& Smith, 2004); creating employment (Faulkner \& Tideswell, 1997; Fredline \& Faulkner, 2002a); developing facilities and infrastructure for the community (Dwyer et al., 2000; Faulkner \& Tideswell, 1997; Fredline \& Faulkner, 2002a; Jones, 2001); enhancing community pride (Dwyer et al., 2000; Faulkner \& Tides- well, 1997; Fredline \& Faulkner, 2002a; Waitt, 2003); and improving the quality of life in general (Faulkner \& Tideswell, 1997; Ohmann et al., 2006), such as the increase in entertainment and cultural activities (Fredline, 2005). On the other hand, negative social-cultural impacts would include overcrowding and traffic congestion (Cegielski \& Mules, 2002; Faulkner \& Tideswell, 1997; Fredline \& Faulkner, 2002a; Kim et al., 2006; Mihalik \& Simonetta, 1999); disruption to normalcy (Dwyer et al., 2000; Faulkner \& Tideswell, 1997); pollution and other environmental problems such as noise and litter (Barker et al., 2002; Dwyer et al., 2000; Faulkner \& Tideswell, 1997; Fredline \& Faulkner, 2002a; Kim et al., 2006); the demonstration effect (Barker et al., 2002; Brunt \& Courtney, 1999; Fredline, 2005); prostitution (Jones, 2001); less accessibility to facilities (Fredline, 2005); social misbehavior (Ohmann et al., 2006); and crime (Barker, 2004; Mihalik \& Simonetta, 1999).

The list of positive and negative impacts is, of course, not exhaustive as impacts are dependent on the situation in each community or destination and how individuals perceive them (Fredline, 2005). Even within the same community, the perception of an impact may be different due to the extent of exposure to the impact (Faulkner \& Tideswell, 1997). Hence, there will be factors or variables that influence the perceptions, making these intrinsic and extrinsic impacts not absolute, but relative to the contexts of the destination (Faulkner \& Tideswell, 1997; Fredline, 2005; Fredline \& Faulkner, 2000).

There are several approaches to assessing social-cultural impacts. One of them is through the perceptions of the impacts by host residents (Fredline et al., 2003a). These types of studies can provide an important "snapshot" assessment of social-cultural impacts at a particular point in time while others may provide a more longitudinal approach (Twynam \& Johnston, 2004; Waitt, 2003). Many researchers (Cegielski \& Mules, 2002; Deccio \& Baloglu, 2002; Faulkner \& Tideswell, 1997; Fredline, 2005; Fredline \& Faulkner, 2000, 2002a; Jones, 2001; Ritchie \& Inkari, 2006; Waitt, 2003) focus on the intrinsic variables and how they affect residents' perceptions. Again, the results of these studies vary from situation to situation $(\mathrm{Oh}$ - 
mann et al., 2006), although some may share similar findings. One example is how interest level affects perceptions, where residents with an interest in the event or attended or watched it on television will have a higher level of support for the event and a more positive attitude towards it than those who did not have any interest (see Cegielski \& Mules, 2002; Fredline, 2005; Fredline \& Faulkner, 2000, 2002a). Conversely, those who had no interest in the event felt particularly negative because they did not perceive sharing in any resulting benefits or rewards (Waitt, 2003).

Likewise, on the involvement variable, through employment or owning a business in the event or tourism industry, the results have also been very close. Fredline and Faulkner (2002a) and Deccio and Baloglu (2002) had similar conclusions: those who were employed within the industry were more positive, believing the events enriched their lives. Still, Waitt (2003) found that involvement through employment had no influence on the Sydney residents he was studying concluding that the majority of all locals were interested in sport. Sociodemographic variables such as age, education, income levels, and place of residence tend to produce varying levels of sociocultural impacts among residents in different cases (Brunt \& Courtney, 1999; Cegielski \& Mules, 2002; Faulkner \& Tideswell, 1997; Fredline \& Faulkner, 2002a, 2002b; Kim \& Petrick, 2005; Ritchie \& Inkari, 2006; Waitt, 2003).

Exploring all these variables simply allows the recognition that not everyone within a destination or community will perceive the impacts in the same way (Waitt, 2003). In the first place, socialcultural impacts are wide-ranging (Barker, 2004). Second, the variables interact to produce different permutations of perceptions. Gursoy and Rutherford (2004) suggest the level of importance placed on a particular impact will affect people's perception of that impact, which may subsequently influence their observations of another impact. Because "events differ in their size, nature, location(s), and duration" (Barker, 2004, p. 176), the resulting impacts of a particular event in a particular destination are always worth exploring.

\section{Social-Cultural Impacts of Car Racing Events}

Car racing events, such as the Formula 1 Grand Prix, can certainly be considered as part of sports event tourism, since they help to attract visitors to a destination, and contribute to visitor arrivals and tourism receipts (Deery, Jago, \& Fredline, 2004). Given the two possible extreme ends of the inclination of fans and enthusiasts towards them, and the aversion of nonfans and nonenthusiasts against the same, there exists a range of possible perceptions to the impacts of this type of sport event (Fredline, 2004).

Exploring past studies into car races and the social-cultural impacts perceived have revealed three cases that provide a somewhat similar situation to the Formula 1 race that was held in Singapore in that the car races were all held on street circuits. The first case is the IndyCar race, held in the Gold Coast, Australia. The street circuit was within the tourism heart and along a major street in Surfers Paradise (Fredline \& Faulkner, 2002a). The second case is the Melbourne Grand Prix, where the street circuit was located in Albert Park, a suburban nontourism area (Fredline \& Faulkner, 2002a). The third is the V8 Supercar Race held in the Parliamentary Precinct of Canberra, Australia. Though not exactly downtown, it was located within an area with institutional buildings and foreign embassies (Cegielski \& Mules, 2002), more of a business area than residential.

The positive impacts of these motor sport events included enhancing the image of the destination, facility maintenance and improvement, community benefits, increased pride, developing and showing off event management skills, improving the quality of life, and enhancing international identity. Negative impacts included noise, parking problems, opportunity costs, traffic, disruption to lifestyle, reduced civil rights and liberties, unbalanced distribution of power, a reduced quality of life, and social misbehavior. In addition, intrinsic variables that were most commonly found to have an influence on the perceptions of the above impacts included proximity to the event, whether the resident was involved in or employed by the event, if they attended or had accessibility to car race area, and the level of interest or identifying with the event. Further, age and education played a role in that younger people were more supportive of the car race while more highly educated residents felt more negative about the event (Cegielski \& Mules, 2002; Fredline, 2004, 2005; Fred- 
line \& Faulkner, 2002a; Fredline, Jago, \& Deery, 2003b).

Car races create their own unique set of impacts and variables influencing their perception. These impacts can be considered differently at both the individual and community level with certain impacts being more pronounced at the individual level rather than at the community level and vice versa (Fredline et al., 2003b). But while some impacts may be unbearable, such as noise or congestion, they last for only a limited duration (Hinch \& Higham, 2004). These negative impacts may be tolerated by individuals and the community in general only because they recognize the overall economic benefits that such an event will bring (Kelly, 2006). Arising from studies into the social-cultural impacts, many researchers (Ap, 1992; Deccio \& Baloglu, 2002; Fredline, 2004; Fredline \& Faulkner, 2000, 2002a; Gursoy \& Kendall, 2006; Kim et al., 2006; Waitt, 2003) framed their explanation of the differences in perceptions with social exchange and social representation theory.

\section{Theoretical Framework}

In understanding the perception of socialcultural impacts of a car race, the social exchange theory is useful for understanding the exchange of resources between individuals and groups, called "actors" (Ap, 1992, p. 668). According to Ap (1992), these resources are highly valued and the exchange takes place when actors believe the benefits will outweigh costs as a result of the resources supplied (Gursoy \& Kendall, 2006). When the exchange is completed, they evaluate the outcome. Actors refer to host residents and the event organizer(s) while resources refer to the extension of hospitality and the provision of entertainment respectively. Residents will extend their hospitality to visitors in exchange for a series of events or subevents that provide entertainment if they believe they will benefit more than the costs involved. However, if, at the end of the exchange, residents do not perceive that they have gained as per their expectations, it will influence their future support for the event.

Using social representation theory, Fredline and Faulkner (2000) explained that representations help people interpret and understand situations go- ing on around them, and these are shared by members of the same society or community such that it aids in a tacit understanding between members of the same group. These social representations, formed from previous knowledge and experience, social interactions and the media (Fredline \& Faulkner, 2000), also serve as reference point for individuals (Fredline \& Faulkner, 2002b; Kim et al., 2006), from which they perceive and interpret new encounters. It is also based on the individual's value system and can be subjected to reevaluation (Kim et al., 2006).

Social representation theory helps to explain the similarities and differences within and between subgroups of a community regarding the perception of an event's social-cultural impacts. Members belonging to the same cluster will often display the same perception of a certain impact. This explains why a group of "ultimate enthusiasts" of car races will not perceive noise as a negative impact while a group of "no-interest-at-all" will perceive it negatively. To the "ultimate enthusiasts," noise is not considered an issue at all because their representations tell them that it is part of the excitement. As for the "no-interest-at-all," it is just intolerable. The hype in the media prior to any event may also have an influence in the reference point of residents, according to Kim et al. (2006), thus reinforcing further the perceptions.

\section{The Formula 1 SingTel Grand Prix in Singapore}

The Formula 1 SingTel Grand Prix (F1) was held for the first time in Singapore, from September 26 to 28,2008 . It presented a brand new opportunity for residents to experience the thrill and action of motor car racing. As seen from the literature review, car racing events present many challenges to authorities and event organizers in terms of managing the social-cultural impacts to residents. Being a new event, it obviously lacked prior data and research, as to how this race impacted host residents. Many of the issues that have been discussed in the literature review will be "tested" in this context. Thus, the key research themes for this study are:

- What are the positive and negative socialcultural impacts of the F1 Grand Prix in Singa- 
pore, and how do they relate to the wider theoretical debates?

- How affected are Singapore residents to these perceived impacts?

- What are the variables influencing their perceptions and support?

- What aspects of these social-cultural impacts should relevant authorities improve?

\section{Methods}

While the literature review raised issues on the social-cultural impacts of car racing events, it also contributed to the nature of the primary research that was collected. It allowed specific areas highlighted to be incorporated within the data collection in order to verify or refute certain patterns in the perceptions of social-cultural impacts. The quantitative technique was preferred over the qualitative for three reasons. First, it was important to gain insights from a sample that could be related to the wider population. Second, a larger sample was required for correlation analysis to demonstrate how impacts may vary among different types of residents. Third, quantitative techniques were also adopted by researchers of previous car races (Cegielski \& Mules, 2002; Fredline, 2005; Fredline \& Faulkner, 2000, 2002a, 2002b; Fredline et al., 2003a, 2003b), thus aiding the comparative analysis.

The sampling frame consisted of Singapore citizens and permanent residents above the age of 20 . Working at a $95 \%$ confidence level, with a margin of error of $10 \%$, a sample size of 96 respondents was required and successfully completed. As the F1 race took place within the city center in Marina Bay, it was situated within a commercial, tourism, and leisure vicinity with offices, hotels, malls, restaurants, and cinemas. Therefore, the issue of residential proximity would not be relevant here. Instead, the concern with the accessibility to those facilities for work or leisure/social purposes around and within the race circuit was explored, together with how frequent the access was. A street survey was conducted at "strategic" spots, such as the entrance/exit of office buildings, malls, the Mass Rapid Transit stations, and pedestrian overhead bridges. This captured people who accessed those facilities in order to collect responses to residents' perceptions on the impacts of the $\mathrm{F} 1$ race.

The survey was conducted about 2 weeks after the $\mathrm{F} 1$ race had ended so that residents could reflect on the impacts. Other researchers also conducted their postevent surveys within this particular time frame (Fredline \& Faulkner, 2002a; Kim $\&$ Petrick, 2005). The responses from the survey were generated through a face-to-face interview. Convenience sampling was used to collect the necessary information, a technique also adopted by Kim et al. (2006). Although this could be prone to bias as not everyone had an equal chance of being selected, and thus may not be fully representative of the wider population, it was more practical than systematic random sampling as that can be difficult in an open public area. However, to ensure representativeness to some degree, interviewers were instructed to balance between a proportionate spread of gender and age group based on the 2007 midyear estimates of demographic profiles indicated in Singapore's Yearbook of Statistics 2008 (Department of Statistics, 2008). A small team of interviewers studying tourism were trained by one of the authors and were given a set of clear instructions on how to approach respondents using a convenience sampling strategy, introduce themselves and the purpose of the survey.

The questionnaire opened with two open-ended questions about positive and negative sociocultural impacts of the F1 race in Singapore followed by a series of prompted sociocultural impact statements derived from the literature to which respondents answered along a 7-point Likert scale of level of agreement. Sociodemographic characteristics were collected at the conclusion of the anonymous survey.

\section{Data Analysis and Discussion}

Table 1 summarizes key sociodemographic (age, gender, educational level) and intrinsic characteristics (level of interest in and attendance at race, frequency and reason for being in race area, involvement with tourism/event industry) of the Singapore residents that took part in the study. These were also variables highlighted in the literature review that had the potential to influence perceptions (Cegielski \& Mules, 2002; Fredline, 2004, 
Table 1

Sociodemographic and Intrinsic Characteristics of Respondents

\begin{tabular}{|c|c|}
\hline Characteristic & $\%(n=96)$ \\
\hline \multicolumn{2}{|l|}{ Gender } \\
\hline Male & $53 \%$ \\
\hline Female & $47 \%$ \\
\hline \multicolumn{2}{|l|}{ Age } \\
\hline 20-39 years old & $49 \%$ \\
\hline 40 years $\&$ above & $51 \%$ \\
\hline \multicolumn{2}{|l|}{ Education } \\
\hline PSLE to O level & $22 \%$ \\
\hline A level to diploma & $46 \%$ \\
\hline Graduate to postgraduate & $32 \%$ \\
\hline \multicolumn{2}{|c|}{$\begin{array}{l}\text { Involvement in tourism or event industry } \\
\text { through employment/business ownership }\end{array}$} \\
\hline Yes & $21 \%$ \\
\hline No & $79 \%$ \\
\hline \multicolumn{2}{|l|}{ Attendance } \\
\hline Purchased ticket & $13 \%$ \\
\hline $\begin{array}{l}\text { Watched from vantage points (e.g., } \mathrm{h} \\
\text { rooms) }\end{array}$ & $19 \%$ \\
\hline Watched on television & $73 \%$ \\
\hline \multicolumn{2}{|l|}{ Interest } \\
\hline Followed F1 race series all the time & $17 \%$ \\
\hline Followed F1 race half the time & $45 \%$ \\
\hline Do not follow race at all & $38 \%$ \\
\hline \multicolumn{2}{|l|}{ Frequency of access to race circuit vicinity } \\
\hline 6-7 days a week & $9 \%$ \\
\hline 3-5 days a week & $32 \%$ \\
\hline 1-2 days a week (weekends only) & $33 \%$ \\
\hline 1-2 days a week (weekdays only) & $25 \%$ \\
\hline \multicolumn{2}{|l|}{ Reason for accessing race circuit vicinity } \\
\hline Work & $25 \%$ \\
\hline Social/leisure & $60 \%$ \\
\hline Work \& social/leisure & $12 \%$ \\
\hline Other & $3 \%$ \\
\hline
\end{tabular}

2005; Fredline \& Faulkner, 2000, 2002a). Correlation analysis (Pearson chi-square) was used to explore possible relationships within the data because the variables used were considered to be categorical in nature, either by the type of respondent (e.g., age, gender, education level) or whether they agreed or disagreed with a certain type of impact. The issue of proximity was studied together with frequency and reason of accessibility as the race circuit was situated within a busy commercial area. Those who accessed that area more frequently and for work (making this an involuntary option similar to place of residence) would likely experience impacts related to proximity as revealed in past literature. Data have been categorized and aggregated for statistical purposes.

\section{Positive Social-Cultural Impacts of the F1 Race on Singapore Residents}

Table 2 identifies unprompted perceived positive social-cultural impacts of the $\mathrm{F} 1$ race among respondents. Impact responses were grouped into various themes, with promoting cultural exchange topping the list and mentioned by $18.7 \%$.

Respondents were then asked to state their level of agreement with a set of prompted positive social-cultural impacts associated with the F1 event. Table 3 demonstrates the strongest agreement was shown for the F1 race promoting Singapore as a tourist destination (95\% of respondents), followed closely by enhancing the image $(94 \%)$.

There were no significant correlations between the positive impacts statements with age, gender, and education. However, the intrinsic variables such as involvement, attendance, interest, and proximity, yielded a few significant relationships with the positive impacts. For involvement, the cross-tabulation analysis $\left[\chi^{2}(1)=4.219\right]$ demonstrated those who were involved in the tourism/ events industry agreed more $(64 \%)$ that learning about other cultures was a positive impact compared to those who were not involved (31\%).

The independent variables related to attendance and interest were divided into four areas: purchased a ticket (direct attendance); watched the race from vantage points (indirect attendance); watched the race from television (interest); and followed the race in its series, either having attended previous F1 races, watched them on television, or read reports about them (interest). Each of these areas was cross-tabulated with the positive impacts to determine any form of associations. Out of these, only those who watched the race from television or followed the race series showed a relationship with the impact on quality of services. It can be seen that in the case of those who watched the race on television $(88 \%)$ or who followed the F1 series (91\%), a higher percentage of them tended to agree that the quality of services in stores and restaurants had improved during the F1 season compared to those who neither watched $(57 \%)$ nor followed the series $(62 \%)\left[\chi^{2}(1)=\right.$ 6.373 , and $\chi^{2}(1)=7.248$, respectively].

Proximity in this research was taken to mean accessibility to the facilities in and around the race 
Table 2

Positive Social-Cultural Impacts of the F1 Race on Singapore Residents

Positive Social-Cultural Impacts (by Themes)

$\%(n=96)$

To promote cultural exchange/interaction/understanding, learn about other culture, opportunity to meet people

$18.7 \%$

To boost economy, create employment, increase business

$16.7 \%$

$15.6 \%$

To demonstrate capability/efficiency/high level of standard in event management

$9.4 \%$

To allow foreigners to know Singapore/Singapore culture better

$8.3 \%$

To promote/publicize/improve awareness of Singapore, global exposure

$8.3 \%$

$7.3 \%$

$7.3 \%$

To have a livelier social scene

$3.1 \%$

To build track record by being the "first"

$3.1 \%$

circuit vicinity in terms of frequency and the reason for doing so. Responses were collapsed into two groups for frequency of access: 3-7 days a week and 1-2 days a week. Reason for access was separated into two groups as well: work only and social/leisure only. Those who had other reasons or who accessed for work and social/leisure purposes were not considered for the analyses. In short, respondents either had to access the race circuit vicinity relatively frequently or infrequently, involuntarily or voluntarily. The reason for splitting into two groups was to ascertain if the involuntary group felt more impacted than the voluntary group. The involuntary group not only had to access the vicinity almost on a daily basis, they also did not have a choice to stay away despite the inconveniences. Therefore, that might affect their responses to the impact of the race. The voluntary group, on the other hand, did so willingly, knowing full well the inconveniences they would have to bear. Hence, they might be more tolerant of the impacts compared to the former group. There was a correlation between frequency of access with the impact on enjoy meeting people of different cultures. It seemed that the less frequent (1-2 days) access they had to the race circuit vicinity, the more respondents agreed to having enjoyed meeting people of different cultures $(78 \%)$, compared to those who had 3-7 days access $(50 \%)\left[\chi^{2}(1)=\right.$ 3.927]. At the same time, a relatively higher percentage of respondents $(78 \%)$ who accessed the race area for social/leisure reasons agreed to this positive impact compared to those who accessed the area for work $(40 \%)\left[\chi^{2}(1)=5.182\right]$.

Table 3

Level of Agreement With Set of Prompted Positive Social-Cultural Impacts of the F1 Race on Singapore Residents

Level of Agreement

Among Respondents $(n=96)$

Positive Social-Cultural Impacts

F1 enhances the overall image of Singapore amongst international visitors

F1 promotes Singapore as a tourism destination

Singaporeans are proud to host the F1 Grand Prix

Singaporeans are able to demonstrate their capabilities in managing an international event

The quality of services in the stores \& restaurants is improved during the F1 season

I learn more about other cultures because of F1 event

I enjoy meeting people of different cultures during the F1 season

There are more activities \& entertainment before/during/after the F1 season

\begin{tabular}{crc}
\hline Disagree & Neutral & Agree \\
\hline $2 \%$ & $4 \%$ & $94 \%$ \\
$2 \%$ & $2 \%$ & $95 \%$ \\
- & $13 \%$ & $87 \%$ \\
$1 \%$ & $9 \%$ & $90 \%$ \\
$11 \%$ & $42 \%$ & $47 \%$ \\
$40 \%$ & $37 \%$ & $23 \%$ \\
$15 \%$ & $50 \%$ & $35 \%$ \\
$18 \%$ & $30 \%$ & $52 \%$ \\
\hline
\end{tabular}

The level of agreement from the original 7-point Likert scale has been aggregated into three categories for statistical purposes. Strongly disagree/disagree/slightly disagree aggregated into disagree, while strongly agree/agree/slightly agree aggregated into agree. 
The analyses have certainly thrown some light on similarities with previous research conducted on car races and some new discoveries of positive social-cultural impacts. The positive impact that garnered the most responses in the open-ended question $(18.7 \%)$ was to promote cultural exchange and interaction and to have the opportunity to meet people. This is a similar finding to studies by Kim et al. (2006) and Waitt (2003). Similarly, the positive impacts on the economy in general and on tourism in particular support those of Fredline (2004) and Fredline et al. (2003a). Another positive impact in this study, which concurred with the research of Fredline (2004), Fredline and Faulkner (2002a), and Fredline et al. (2003a), was the ability for Singaporeans to demonstrate their capabilities in managing an international event. Likewise, the impacts of promoting Singapore and creating a global awareness of the destination, to enhance her status internationally, and to have a livelier social scene all confirmed the research of Cegielski and Mules (2002), Fredline (2004, 2005), Fredline and Faulkner (2002a), and Fredline et al. (2003a).

The cross-tabulations of age, gender, and education found no significant correlations with any of the positive social-cultural impacts (i.e., Singaporean respondents were fairly heterogeneous with regard to their attitudes). This finding contrasted with those of Fredline and Faulkner (2002a), who found significant differences in age and education to the perception of impacts of motor sport events.

Residents' involvement was also associated with learning more about other cultures, a slight similarity to Fredline (2004) and Fredline and Faulkner (2002a), which showed that those who were involved were more positive to the impacts. Perhaps those who were economically dependent on visitors were more prepared to view these encounters with foreign cultures more positively, as explained by Fredline (2004), using social exchange theory. It could be argued those who had an interest in the F1 event perceived the improved quality of services as an improvement to their quality of life, supporting the findings of Cegielski and Mules (2002), Fredline (2004), and Fredline and Faulkner (2000, 2002a).

Regarding proximity, there were significant differences in the frequency and reason of access with enjoy meeting people of different culture because those who had to access the race vicinity frequently and for work did not perceive meeting people, especially on a social platform, as a benefit to them. These respondents were not there to socialize. Therefore, this did not create a heightened perception of this impact as positive.

Overall, the analyses of the positive socialcultural impacts of the F1 race in Singapore demonstrates there was a high level of homogeneity among those surveyed. Using social exchange theory, these results confirmed that the respondents entered into the exchange with the belief that benefits would outweigh costs. This may have been based on the city's past experiences in hosting international events. Using the social representation theory, due to the excitement of this first-ever F1 race in Singapore, and one that was also the inaugural night race, this event created a shared novel experience within the entire community, which helped form positive representations, almost regardless of differences between subcommunities. Hence, there were minimal significant differences between different types of residents to their perceptions.

\section{Negative Social-Cultural Impacts of the F1 Race on Singapore Residents}

Table 4 identifies unprompted perceived negative social-cultural impacts of the $\mathrm{F} 1$ race among respondents and as before responses were grouped into various themes. While cultural disagreements/ being exposed to negative aspects of foreign cultures was cited the most $(9.4 \%)$, generally smaller proportions of respondents identified a negative impact.

Respondents were similarly asked a series of prompted questions pertaining to negative socialcultural impacts. Table 5 indicates the impacts that most respondents agreed had impacted them were traffic congestion (72\%) and difficulty in accessing facilities near or around the race circuit (70\%).

Cross-tabulations were run against the series of negative social-cultural statements with sociodemographic and intrinsic variables. Gender showed no significant relationship with any of the negative impacts while a few correlations emerged with age 
Table 4

Negative Social-Cultural Impacts of the F1 Race on Singapore Residents

Negative Social-Cultural Impacts (by Themes)

$\%(n=96)$

Cultural disagreement/differences/misunderstanding, exposure to negative aspects of foreign cultures

Road blocks or closures

$8.3 \%$

Encourage gambling

$8.3 \%$

$7.3 \%$

Pollution-in general, noise, littering

$7.3 \%$

$6.3 \%$

Too much money spent, waste of money to build infrastructure, could have used money for charity

Congestion \& crowding in public transport

$6.3 \%$

$6.3 \%$

Encourage speeding

$4.2 \%$

Negative economic impacts

Inconvenience \& disruption

$4.2 \%$

Negative social activities \& behavior

and education level. A higher percentage of respondents (94\%) from those 40 years and older tended to agree with the impact of unbalanced distribution of costs as compared to those 39 years and younger $(72 \%)\left[\chi^{2}(1)=5.652\right]$.

The education level of respondents, from PSLE-O Level, A Level-Diploma, and up to Graduate-Postgraduate, had an influence with four negative impacts. Overall, the higher the education level, the lesser percentage of respondents agreed to the perception that the investment in hosting the
F1 could have been better spent in other areas such as social welfare schemes $\left[\chi^{2}(2)=7.849\right]$. However, the higher education level also showed a significantly greater percentage of respondents agreeing to noise generated $\left[\chi^{2}(2)=7.452\right]$, traffic congestion $\chi^{2}(2)=7.960$ ], and more crowding in public places during the F1 season $\left[\chi^{2}(2)=8.274\right]$.

The cross-tabulations also showed two significant relationships for the level of involvement. A higher percentage of those who were involved in the tourism/events industry seemed to be affected

Table 5

Level of Agreement With Set of Prompted Negative Social-Cultural Impacts of the F1 Race on Singapore Residents

\begin{tabular}{|c|c|c|c|}
\hline \multirow[b]{2}{*}{ Negative Social-Cultural Impacts } & \multicolumn{3}{|c|}{$\begin{array}{l}\text { Level of Agreement } \\
\text { Among Respondents } \\
\qquad(n=96)\end{array}$} \\
\hline & Disagree & Neutral & Agree \\
\hline F1 encourages dangerous driving & $51 \%$ & $22 \%$ & $27 \%$ \\
\hline F1 encourages a more elitist society & $21 \%$ & $29 \%$ & $50 \%$ \\
\hline $\begin{array}{l}\text { The investment in hosting F1 could be better spent on other areas such as social welfare } \\
\text { schemes }\end{array}$ & $20 \%$ & $34 \%$ & $46 \%$ \\
\hline $\begin{array}{l}\text { There is an unbalanced distribution of benefits-only some people/organisations benefit } \\
\text { from the F1 event }\end{array}$ & $3 \%$ & $32 \%$ & $65 \%$ \\
\hline $\begin{array}{l}\text { There is an unbalanced distribution of costs-only some people/organisations are inconve- } \\
\text { nienced because of the F1 event }\end{array}$ & $12 \%$ & $28 \%$ & $60 \%$ \\
\hline $\begin{array}{l}\text { have difficulty accessing the facilities (e.g., offices, malls, restaurants, cinemas, etc.) } \\
\text { near/around the race circuit vicinity during the F1 season }\end{array}$ & $8 \%$ & $22 \%$ & $70 \%$ \\
\hline My usual lifestyle/routine is disrupted during the $\mathrm{F} 1$ season & $34 \%$ & $27 \%$ & $39 \%$ \\
\hline There is noise generated by the race & $10 \%$ & $31 \%$ & $59 \%$ \\
\hline There is traffic congestion during the F1 season & $9 \%$ & $19 \%$ & $72 \%$ \\
\hline There is more crowding in public places during the $\mathrm{F} 1$ season & $9 \%$ & $24 \%$ & $67 \%$ \\
\hline
\end{tabular}

The level of agreement from the original 7-point Likert scale has been aggregated into three categories for statistical purposes. Strongly disagree/disagree/slightly disagree aggregated into disagree, while strongly agree/agree/slightly agree aggregated into agree. 
by the noise $(85 \%)\left[\chi^{2}(1)=4.055\right]$ and traffic congestion $(100 \%)\left[\chi^{2}(1)=4.055\right]$ compared to those who were not involved $(54 \%$ and $73 \%$, respectively). Respondents who purchased a ticket to the race and attended were less likely to agree they were negatively affected by traffic congestion $(60 \%)$ $\left[\chi^{2}(1)=9.103\right]$ and crowding of public places $(67 \%)\left[\chi^{2}(1)=4.190\right]$ compared to those who did not buy a ticket (93\% and $91 \%$, respectively). Respondents who watched the race on television were more likely to agree the F1 event encouraged a more elitist society $(79 \%)\left[\chi^{2}(1)=5.785\right]$ and a perceived disruption of to local lifestyles and routines $(63 \%)\left[\chi^{2}(1)=4.153\right]$ compared to those who did not view the race $(50 \%$ and $36 \%$, respectively).

Cross-tabulations with proximity (frequency of access to race circuit vicinity and reason for accessing) produced a number of significant relationships with the negative impacts. A greater proportion of respondents (90\%) who had only 1-2 days access, perceived an unbalanced distribution of costs, compared to those with more access, 3-7 days $(71 \%)\left[\chi^{2}(1)=4.100\right]$ to the race vicinity. Naturally, those who had to access the race circuit vicinity more frequently also found difficulty in accessibility, as evidenced by $97 \%$ of these respondents who agreed to the problem, significantly different compared to $82 \%$ of those who accessed the vicinity less frequently $\left[\chi^{2}(1)=4.861\right]$. Likewise, $79 \%$ of the respondents who had to access the race circuit vicinity more frequently agreed with the disruption the F1 event brought onto their lifestyle or routine, also significantly different compared to just $31 \%$ of those who accessed it less frequently $\left[\chi^{2}(1)=16.818\right]$.

Frequency of access was also found to have significant relationships with noise, traffic congestion, and crowding, with almost similar results from the cross-tabulations. All respondents who had to access the race circuit vicinity more frequently were found to agree with all the three negative problems, significantly more compared to those who had less access $\left[\chi^{2}(1)=10.439,8.720\right.$, and 7.577, respectively]. The reason for accessing the race circuit vicinity was also found to have an association with disruption of lifestyle/routine. Some other relationships emerged from the analysis of the data with regard to access issues. Gener- ally those who had access to the area for work agreed they were more negatively impacted by noise, traffic congestion, and more crowding compared to those respondents only in the area for social/leisure purposes $\left[\chi^{2}(1)=4.417,4.115\right.$, and 4.001 , respectively]. Further, those who access the area for work $(81 \%)$ agreed the race disrupted local lifestyles and routines compared to those there for social/leisure reasons $(43 \%)\left[\chi^{2}(1)=8.253\right]$.

When it came to the perception of negative social-cultural impacts of the F1 race in Singapore, respondents raised several points that bore similarities to previous studies conducted on car race. Road blocks or closures alluded to the inconvenience, traffic congestion, and disruption to normal life, especially for those who had to access the race circuit vicinity. These impacts support similar issues raised by Cegielski and Mules (2002), Fredline (2004), Fredline and Faulkner (2002a), and Fredline et al. (2003b).

Another similar finding mentioned by the researchers was pollution, especially noise and littering. Respondents who felt that too much money was spent on hosting the F1 race, including money used for the maintenance of roads when the race was over, may have implied the recognition of an opportunity cost, mentioned by Fredline (2004). Negative economic impacts, another opportunity cost, could also be due to the road closures which affected businesses within the race circuit vicinity.

The perception that $\mathrm{F} 1$ and speeding went hand-in-hand was an issue along a similar track on the point about dangerous driving, which Fredline (2004) mentioned citing Fisher et al. (1986). Negative social activities and behavior, including prostitution, were likewise found by Fredline et al. (2003a) and Jones (2001). And though mentioned by only one or two respondents, issues such as the demonstration effect (portraying Singapore as a "Western wannabe") were similar to what Barker et al. (2002), Brunt and Courtney (1999), and Fredline (2005) identified; and the competition for the use of roads, similarly cited by Melbourne residents in Albert Park, where the Melbourne Grand Prix was held (Fredline 2004).

Three unprompted negative impacts among Singaporean respondents should also be noted, because they were previously not mentioned in any of the previously researched car races. These re- 
late to the perception that the F1 event brought about cultural disagreement, differences, and misunderstanding; encouraged gambling; and emphasized the differences in social status, thus causing social separation between the "haves" and the "have-nots."

Social exchange theory explains why some of these impacts were mentioned by respondents. Issues such as road blocks and closures, opportunity costs, congestion and crowding, inconvenience, and disruption could be due to the fact that respondents did not see themselves benefiting from the F1 event, and thus viewed the exchange negatively. According to Ap (1992), residents would only tolerate the negative impacts if they believed the benefits outweighed the costs. Perhaps in this study, the sample of respondents did not share this belief. On the other hand, social representation theory can explain some of the other impacts perceived by respondents, such as cultural disagreement and differences in social status. Perhaps within an Asian society, the reference point for social cohesiveness is one where harmony exists (Chan, 2005). Despite the progress Singapore has made into becoming a global city-state, many residents cling to their traditional Asian roots. Hence, their reference point would suggest that any of such foreign cultures displayed, with the flaunting of wealth and being seen as belonging to an upper social class, would conflict with their original reference point. Therefore, their perception of what the F1 race seemed to suggest (a clash with foreign cultures) was greatly influenced as a result of these new encounters (Fredline \& Faulkner, $2002 b)$. Local media reports may have also influenced some of these perceptions, such as the negative economic impacts.

The results of the cross-tabulations also presented some enlightened findings. The association between age and the perception of unbalanced distribution of costs could be due to the fact that the older respondents were more discerning in the costs and benefits of the entire event, having experienced or known how previous events had fared in this particular area. At the same time, this particular group probably did not identify as much with the F1 event as the younger group, hence there was more agreement to the impact of unbalanced distribution costs, seeing themselves on the receiving end of the inconveniences. To them, the exchange was viewed with costs greater than benefits.

The significant influence of education levels with the impact that the investment could have been better spent elsewhere probably suggested that the lower educated respondents did not see themselves on the receiving end of any of the benefits of this event either, hence the perception of this negative impact was readily agreed to. Of course the reverse would be true of those higher educated, where they saw the F1 event as part of their lifestyle, providing activities and entertainment to enrich their lives. Therefore, they were less likely to agree to this impact. Further analyses of education with noise, traffic congestion, and more crowding in public places all show a similar trend to Fredline and Faulkner (2002a). The higher the level of education, a progressively greater percentage of respondents were in agreement to these negative impacts. So while they enjoyed some of the benefits brought about by the F1 event, these aspects were, perhaps, not seen to be sufficient for them to tolerate the negative aspects (Ap, 1992; Kelly, 2006). However, the more highly educated were also less affected by the noise. The data may assume that perhaps the higher educated did not work the evening or weekend hours when the race took place compared to others and hence they were not as much affected these negative impacts.

The nature of involvement showed a slight difference to the previous studies of Fredline (2004) and Fredline and Faulkner (2002a), who did not find those involved to be negatively impacted. However, in this study, it was found that those who were involved in the tourism/events industry possessed a higher percentage of respondents who were affected by the noise and traffic compared to those who were not involved. One possibility could be this particular group of respondents worked near or around the race circuit vicinity - an area high in tourism activities (proximity factor) - and therefore were at the receiving end of these negative impacts because they were not able to voluntarily stay away from the area.

With regard to attendance and interest, those who purchased a ticket to watch the F1 race were less likely to agree that traffic and overcrowding were a problem compared to those who did not. 
Similar to Fredline and Faulkner's (2000) finding, spectators tended to disagree with the negative impacts. In this exchange, individuals expected benefits greater than costs; hence they were more tolerant of negative aspects (Ap, 1992). However, for those who watched the race on television, a higher percentage of them agreed that the event encouraged a more elitist society and had more disruption in their lifestyle/routine. In the first instance, images seen on television might have conflicted with their own beliefs or reference points and hence, eliciting a negative perception of the event. In the second instance, respondents believed the disruption far outweighed the benefits, even the benefit of watching it "live." Perhaps that was why they would rather stay at home to watch the event. These could be the marginal enthusiasts.

Finally, relating to proximity, the cross-tabulations of frequency in accessing the race circuit vicinity with the negative impacts produced the most number of significant relationships. These differences were in the perception of unequal distribution of costs, difficulty in accessing the facilities near or within the vicinity, disruption of lifestyle or routine, noise, traffic congestion, and more crowding in public places. These results mirror the findings of Cegielski and Mules (2002), Fredline (2004), and Fredline and Faulkner (2002a), where those living in close proximity (in this case, frequently accessed) perceived more negative impacts. Certainly for this group who had to access the area almost on a daily basis, no amount of benefits would outweigh the problems they faced during the F1 race. They would certainly be most unwilling to enter into the exchange again, unless problems were alleviated. To further confirm this point made, it was the group who had to access the area due to work that were very much in agreement with the disruption, noise, traffic, and crowding created. This group was also significantly more affected by the noise and traffic, a point that was alluded to earlier on. Proximity in this survey, as in other research on car race, was a major factor influencing the perception of negative impacts of the F1 race in Singapore.

The exploration of positive and negative socialcultural impacts has highlighted the fact that there were not as many significant differences in responses to the community-related impacts, such as promoting Singapore as a tourism destination, as individual-related impacts, such as traffic congestion. This implied that not every individual within a community benefited or suffered equally from the impacts of this event (Getz, 1991; Hall, 1992). It depended on their weighing of the cost-benefit scale of the exchange and the representations with which they interpreted the impacts. Further, Singaporeans were much more homogenous about the way they perceived they were affected positively by the event compared with the array of negative impacts.

\section{Conclusions and Recommendations}

The aim of this research sets out to examine Singapore residents' perceptions of the socialcultural impacts of the F1 race. In particular, four crucial questions were established after a thorough review of past studies that guided the process to achieve this aim. What are the positive and negative social-cultural impacts of the F1 Grand Prix in Singapore, and how do they relate to the wider theoretical debates? How affected are Singapore residents to these perceived impacts? What are the variables influencing their perceptions and support? Data from these first three questions are used to answer the final query, namely what aspects of these social-cultural impacts should relevant authorities improve?

The research has certainly provided insights and answers to the first three research areas. Positive and negative social-cultural impacts of the F1 race perceived by the residents were ascertained through their responses to the survey. Some of these impacts, especially the negative ones related to noise, traffic congestion, and crowding, affected certain respondents more than others. Other impacts, such as having more activities and entertainment, provided an opportunity for residents to enjoy the benefits of the F1 race. Because individual respondents perceived these impacts differently, variables that influenced those perceptions were also established. Social exchange and social representation theories further aided in the understanding of these differences. All these findings also provided a source of input as to the areas relevant authorities could improve in the subsequent years. Even if residents' perceptions may be instinctive, 
as suggested by Fredline (2005), respondents in this study have, nevertheless, provided some valid suggestions on the areas for improvement. Authorities involved should consider them seriously.

One of the pressing issues for improvement was traffic. Congestion was presented as a problem, followed closely by some form of difficulty in accessing the facilities in and around the race circuit vicinity. Closely related to traffic management was the area of road closure. Recalling that road blocks or closures were problems cited by some respondents, it should be no surprise that this area was presented as crucial for improvement in subsequent F1 races. In fact, the common suggestion for tackling the problem of road closure was to close the roads for a shorter duration. In the inaugural race that took place, authorities closed the roads for a total of 13 days, including pre- and postrace days, for the installation and dismantling of temporary race infrastructures (Land Transport Authority, 2008; Lim \& Yeo, 2008), which led to traffic jams and delays, especially on the initial days of closures (Huang, 2008).

Three other points made by respondents referred to promoting the event more intensively to the general public/locals, engaging them in more ways, and lowering ticket prices. Respondents felt that the promotion and publicity should have reached out more to the "heartlands," a term used in Singapore to refer to suburbs with a high residential population, so that residents would feel more involved, excited, and informed about the event and the nature of the race. A respondent suggested educating the public to the history of F1, or to have F1 car models within suburban malls to allow residents to have photos taken. These initiatives would help to engage them, and generate interest and enthusiasm for the event. As for the issue with ticket prices, the idea was to make this event more affordable to the general public so that more could be involved. These suggestions are perhaps, a way to minimize the perception that F1 creates a difference in social status.

With the above suggestions, it also paves the way for future research into this area. The survey could be conducted on a wider geographical area in Singapore, instead of just limiting it within a certain locality as in this research. In this way, a more global response could be garnered, produc- ing a deeper understanding of the perception of host residents regarding the impacts generated by the $\mathrm{F} 1$ race.

The research into perceptions of social-cultural impacts should also take on a more longitudinal approach, especially for recurring events (Barker et al., 2002). This involves conducting studies not only before and after a particular F1 season, but also over a period of a few seasons. Obviously, this approach yields much advantage. Firstly, it is not only possible to determine if perception has changed prior to and after an event, but also if these changes, if any, are sustained over a much longer period of time. According to social exchange theory, exchange relationships are not static but fluid (Waitt, 2003). Certainly, when this euphoric stage has passed, and residents move on to subsequent seasons of F1 in Singapore, they could become more rational and consider even more carefully the true worth of the exchange, and then act accordingly. Sustained support for future events would not be possible if their postevent evaluation of the exchange falls below their initial expectations (Gursoy \& Kendall, 2006). Hence, it is important to ascertain any changes in perception over time. More importantly, the causes for the changes have to be investigated (Kim et al., 2006).

In addition to conducting research into the social-cultural impacts of the F1 race, economic and environmental impacts should also be embarked on so as to manage the event in a more holistic way (Barker et al., 2002; Fredline et al., 2003). Relevant authorities should ensure a long-term sustainability in all these areas, especially when events become a mainstay in the marketing of the destination. Naturally, all the above recommendations would involve more resources, both financial and human. But it is a worthwhile investment. Stakeholders' input should be seriously taken into consideration to ensure their continued support.

\section{References}

Ap, J. (1992). Residents' perceptions on tourism impacts. Annals of Tourism Research, 19(4), 665-690.

Ap, J., \& Crompton, J. L. (1993). Residents' strategies for responding to tourism impacts. Journal of Travel Research, 33(1), 47-50.

Ap, J., \& Crompton, J. L. (1998). Developing and testing a tourism impact scale. Journal of Travel Research, 37(2), 120-130. 
Barker, M. (2004). Crime and sport events tourism: The 1999-2000 America's Cup. In B. W. Ritchie \& D. Adair, D. (Eds.), Sport tourism. Interrelationships, impacts, and issues (Ch. 9, e-book). Clevedon, UK: Channel View Publications.

Barker, M., Page, S. J., \& Meyer, D. (2002). Evaluating the impact of the 2000 America's Cup on Auckland, New Zealand. Event Management, 7(2), 79-92.

Besculides, A., Lee, M. E., \& McCormick, P. J. (2002). Residents' perceptions of the cultural benefits of tourism. Annals of Tourism Research, 29(2), 303-319.

Boyko, C. T. (2008). Are you being served? The impacts of a tourist hallmark event on the place meanings of residents. Event Management, 11(4), 161-177.

Brown, G., Chalip, L., Jago, L., \& Mules, T. (2002). The Sydney Olympics and Brand Australia. In N. Morgan, A. Pritchard, \& R. Pride (Eds.). Destination branding: Creating the unique destination proposition (Ch. 10, ebook). Oxford: Butterworth-Heinemann.

Brunt, P., \& Courtney, P. (1999). Host perceptions of sociocultural impacts. Annals of Tourism Research, 26(3), 493-515.

Cegielski, M., \& Mules, T. (2002). Aspects of residents' perceptions of the GMC 400-Canberra's V8 Supercar Race. Current Issues in Tourism, 5(1), 54-70.

Chan, B. (2005). From West to East: The impact of culture on personality and group dynamics. Cross Cultural Management, 12(1), 31-45.

Cohen, E. (1988). 1988 tourism and aids in Thailand. Annals of Tourism Research, 15, 467-486.

Deccio, C., \& Baloglu, S. (2002). Non-host community resident reactions to the 2002 Winter Olympics: The spillover impacts. Journal of Travel Research, 41(1), 46।-56.

Deery, M., Jago, L., \& Fredline, E. (2004). Sport tourism or event tourism: Are they one and the same? Journal of Sport Tourism, 9(3), 235-245.

Department of Statistics, Ministry of Trade \& Industry. (2008). Yearbook of statistics Singapore, 2008. Retrieved September 22, 2008, from http://www.singstat. gov.sg/pubn/reference/yos/yos2008.pdf

Dolles, H., \& Söderman, S. (2008). Mega-sporting events in Asia-Impacts on society, business, and management: An introduction. Asian Business \& Management, $7(2), 147-162$.

Douglas, N., Douglas, N., \& Derrett, R. (Eds.). (2001). Special interest tourism: Context and cases. Australia: John Wiley and Sons.

Dwyer, L., Mellor, R., Mistilis, N., \& Mules, T. (2000). A framework for assessing "tangible" and "intangible" impacts of events and conventions. Event Management, 6(3), 175-189.

Faulkner, B., Chalip, L., Brown, G., Jago, L., March, R., \& Woodside, A. (2001). Monitoring the tourism impacts of the Sydney 2000 Olympics. Event Management, 6(4), 231-246.

Faulkner, B., \& Tideswell, C. (1997). A framework for monitoring community impacts of tourism. Journal of Sustainable Tourism, 5(1), 3-28.
Fischer, A., Hatch, J., \& Paix, B. (1986). Road accidents and the grand prix. In J. P. A. Burns, J. H. Hatch, \& T. J. Mules (Eds.), The Adelaide Grand Prix: The impact of a special event (pp. 151-168). Adelaide: The Center for South Australian Economic Studies.

Fredline, E. (2004). Host community reactions to motorsport events: The perception of impact on quality of life. In B. W. Ritchie \& D. Adair, D. (Eds.), Sport tourism. Interrelationships, impacts, and issues (Ch. 8, e-book). Clevedon, UK: Channel View Publications.

Fredline, E. (2005). Host and guest relations and sport tourism. Sport in Society, 8(2), 263-279.

Fredline, E., \& Faulkner, B. (1998). Resident reactions to a major tourism event: The Gold Coast Indy Car Race. Festival Management \& Event Tourism, 5, 185-205.

Fredline, E., \& Faulkner, B. (2000). Host community reactions. A cluster analysis. Annals of Tourism Research, 27(3), 763-784.

Fredline, E., \& Faulkner, B. (2002a). Residents' reactions to the staging of major motorsport events within their communities: A cluster analysis. Event Management, 7(2), 103-114.

Fredline, E., \& Faulkner, B. (2002b). Variations in residents' reactions to major motorsport events: Why residents perceive the impacts of events differently. Event Management, 7(2), 115-125.

Fredline, E., Jago, L., \& Deery, M. (2003a). The development of a generic scale to measure the social impacts of events. Event Management, 8(1), 23-37.

Fredline, E., Jago, L., \& Deery, M., (2003b). Host community perceptions of the impact of events. A comparison of different event themes in urban and regional communities. Retrieved August 23, 2008, from http://www.crc tourism.com.au/bookshop/2/default.aspx

Getz, D. (1991). Festivals, special events, and tourism. New York: Van Nostrand Reinhold.

Getz, D. (2007). Event studies. Theory, research, and policy for planned events. Burlington, MA: ButterworthHeinemann.

Gursoy, D., \& Kendall, K. W. (2006). Hosting mega events. Modeling locals' support. Annals of Tourism Research, 33(3), 603-623.

Gursoy, D., \& Rutherford, D. (2004). Host attitudes toward tourism. An improved structural model. Annals of Tourism Research, 31(3), 495-516.

Hall, M. (1992). Adventure, sport, and health tourism. In B. Weiler \& M. Hall (Eds.). Special interest tourism. London: Belhaven.

Hinch, T., \& Higham, J. (2004). Sport Tourism Development [e-book]. Clevedon, UK: Channel View Publications.

Huang, R. (2008, September 23). Road closures due to F1 lead to traffic jams in some areas. Channel NewsAsia. Retrieved October 27, 2008, from http://www.channel newsasia.com/stories/singaporelocalnews/view/377893/ 1.html

Jago, L., Chalip, L., Brown, G., Mules T., \& Ali, S. (2003). 
Building events into destination branding. Event Management, 8(1), 3-14.

Johnson, J. D., Snepenger, D. J., \& Akis, S. (1994). Residents' perceptions of tourism development. Annals of Tourism Research, 21(4), 629-642.

Jones, C. (2001). Mega-events and host-region impacts: Determining the true worth of the 1999 Rugby World Cup. International Journal of Tourism Research, 3(3), 241-251.

Kelly, I. (2006). Peace through tourism: A SWOT analysis. Retrieved August 21, 2008, from http://www.iipt.org/ educators/OccPap02.pdf

Kim, H. J., Gursoy, D., \& Lee, S. B. (2006). The Impact of the 2002 World Cup on South Korea: Comparisons of pre- and post-games. Tourism Management, 27(1), 86-96.

Kim, S. S., \& Petrick, J. F. (2005). Residents' perceptions on impacts of the FIFA 2002 World Cup: The case of Seoul as a host city. Tourism Management, 26(1), $25-38$.

Land Transport Authority. (2008). Road closure \& public transport guide. Retrieved October 27, 2008, from http://www.lta.gov.sg/doc/F1\%20Brochure.pdf

Lim, L., \& Yeo, G. L. (2008, July 3). Major road closures during Singapore's F1 race. The Straits Times. Retrieved July 3, 2008, from http://www.straitstimes.com/ Latest\%2BNews/Singapore/STIStory_254213.html

Mihalik, B. J., \& Simonetta, L. (1999). A midterm assessment of the host population's perceptions of the 1996 Summer Olympics: Support, attendance, benefits, and liabilities. Journal of Travel Research, 37(3), 244-248.

Ministry of Trade \& Industry. (2008). Speech by Mr Lim Hng Kiang, Minister for Trade \& Industry, at the groundbreaking of the Pit Building for Formula 1 Singapore Grand Prix, 31 August 2008. Retrieved December 2, 2008, from http://app.mti.gov.sg/default.asp?id $=148 \&$ articleID $=9941$
Ohmann, S., Jones, I., \& Wilkes, K. (2006). The perceived social impacts of the 2006 football world cup on Munich residents. Journal of Sport \& Tourism, 11(2), 129152.

Pizam, A. (1978). Tourism's impacts: The social costs to the destination community as perceived by its residents. Journal of Travel Research, 16(4), 8-12.

Richards, G. (2007). Culture and authenticity in a traditional event: The views of producers, residents, and visitors in Barcelona. Event Management, 11(1), 33-44.

Ritchie, B. W., \& Inkari, M. (2006). Host community attitudes towards tourism and cultural tourism development: The case of the Lewes District, Southern England. International Journal of Tourism Research, 8(1), $27-44$.

Small, K. (2007). Social dimensions of community festivals: An application of factor analysis in the development of the Social Impact Perception (SIP) scale. Event Management, 11(1), 45-55.

Small, K., Edwards, D., \& Sheridan, L. (2005). A flexible framework for evaluating the sociocultural impacts of a (small) festival. International Journal of Event Management Research, 1(1), 66-77.

Twynam, G. D., \& Johnston, M. (2004). Changes in host community reactions to a special sporting event. $\mathrm{Cur}$ rent Issues in Tourism, 7(3), 242-261.

Waitt, G. (2003). Social impacts of the Sydney Olympics. Annals of Tourism Research, 30(1), 194-215.

Wood, E. H. (2005). Measuring the economic and social impacts of local authority events. International Journal of Public Sector Management, 18(1), 37-53.

Xiao, H., \& Smith, S. L. (2004). Residents' perceptions of Kitchener-Waterloo Oktoberfest: An inductive analysis. Event Management, 8(3), 161-175. 